emotional support. Autumn 2015 - core café opening hours set at 9 am to $5 \mathrm{pm}$ following pilots for breakfast and evening trade. Room hire - two upstairs rooms hired out on long term let plus one larger room for ad hoc bookings (light exercise classes, business meetings, special occasions e.g., wakes, christenings, and birthdays). The Mill Outside - outside catering service started summer 2015; attends country shows, special occasions and hospice events. Special Christmas events e.g., themed afternoon tea, party bookings, tea with Father Christmas from 2015. Patient education programme, STREAM, for cancer related fatigue - open to non-hospice patients - started March 2016. Introduced monthly evening theme nights in May 2016 - Tapas, French, Seafood, World Curry.

Results Include Since opening in Nov 2014 to end of the last financial year: Percentage increase in income and visitors per day: café sales by $88 \%$; donations via The Mill to the hospice by $167 \%$; visitors to the café by $61 \%$. Advisors support as many people that are not known to the hospice as are known. Patient outcomes for STREAM programme using the Chalder Fatigue Scale $-86 \%$ felt their fatigue had improved. Promotional competition for afternoon tea vouchers reaches 79000 people.

The Future Plans for The Mill Phase 2 include expansion of the café to provide extra seating at busy times, two additional function rooms and increased trading opportunities.

\section{P-43 ENGAGING COMMUNITIES IN LIFE AND DEATH CONVERSATIONS}

Ian Leech. St Giles Hospice, Lichfield, UK

\subsection{6/bmispcare-2017-hospice.70}

Background As part of our commitment to create Compassionate Communities we have developed a series of Conversation Boards to enable people, not only to talk but also to think about conversations relating to death, dying and bereavement.

Aims To engage our communities in non-pressurised conversations around death, dying and bereavement and create a place for related literature to be available.

Method Each year we ask our communities a different question, the answers are then placed on a board alongside relevant materials that viewers of the board can freely take. Before I die, I want to .... Inspired by Candy Chang, our first life and death conversation in 2014 asked people of all ages across our communities what is top of their bucket list.

I Want to be Remembered In 2015 we asked people how they wanted to be remembered or what they wanted to be remembered for. My funeral song. Music plays a big part in peoples' lives so for 2016 we asked people to choose the one song they would want to be played at their funeral. What makes life worth while. We often talk of care being centred on the person, but to do that we have to discover what matters to those people we care for.

Results Since 2014 this project has enabled hundreds of timely conversations in a way that suits each individual. Over 100 pieces of death, dying and bereavement related literature is taken each month.

Conclusion Not everyone is comfortable talking about death, but in our conversation boards, we have found a way not only to communicate with people on their terms. It has helped us to discover what is important to people in our community and made us think about how we can realise their wishes.

\section{P-44 COMMUNITY ENGAGEMENT NETWORKS}

Vicky Lander. Oakhaven Hospice Trust, Lymington, UK

10.1136/bmispcare-2017-hospice.71

Earlier this year, St Richard's Hospice and St Giles Hospice, both located in the The Midlands, joined forces to instigate a network of those people employed in hospices with the remit and title of Community Engagement. After a successful gathering in February at St Giles, the initiative has gone from strength to strength with another Midlands network held in May. In addition, as a guest member of the Midlands group, being based at Oakhaven Hospice in Hampshire, I took up the challenge to set up a similar network for hospices along the South Coast. This has proved equally successful with a number of hospices contributing to our first forum in June. The networks are aimed at raising awareness, increasing understanding and accessing seldom heard groups in hospice care and not necessarily community fundraisers, unless the remit of the role encompasses both. Bringing hospices' staff together, specifically people whose remit is titled Community Engagement, yet with a plethora of interpretations of the title, has proved valuable for sharing learnings, debating topics and building on new ideas. This initiative of Networks dovetails into the Hospice UK strategy goal no.3 'strive to build community capacity and resilience to care for those at the end of life' and we are keen to promote other regions to follow our lead. Our poster is aimed to encourage conference attendees to consider how they might take forward the Community Engagement network initiative for their regions.

\section{P-45 LEEDS COMPASSIONATE COMMUNITIES - IMPROVING END OF LIFE CARE FOR ALL}

Peter McEvoy. St. Gemma's Hospice, Leeds, UK

\subsection{6/bmjspcare-2017-hospice.72}

Background We are receiving 50\% fewer clinical referrals from Black Asian Minority Ethnic (BAME) communities in the Leeds 7 and 8 postcode areas compared to LS17. We had insufficient evidence to substantiate the specific needs of local BAME communities. A Third Sector Health Grant funded a research project to understand more fully the issues and barriers around communication and language, culture and religion.

Aims The project aimed to improve the support, access and care provided at a person's end of life by ensuring that St. Gemma's services are accessible and culturally appropriate for the BAME communities living in the LS7 and LS8 areas of Leeds.

Methods Developed innovative working relationship with Leeds Involving People (LIP) a service-user led organisation specialising in connecting citizen insight with service redesign. We commissioned LIP to engage with and conduct a survey across BAME community groups to gather quantitative responses and undertake specific focus group work to gain more qualitative responses from harder to reach communities. 
Results In total 1012 BAME people were engaged with; 804 completed questionnaires and 208 took part in 11 focus groups.

Conclusions Whilst it was true that there were religious and cultural barriers preventing local BAME communities accessing our services, what proved more prolific was the lack of awareness of the actual services provided. This research contains a wealth of knowledge about the religious needs of the communities engaged with, and suggestions from the actual communities about how they can be met. They acknowledged how we are already meeting their needs in some respects but highlighted that there were some barriers that simply could not be overcome. The key recommendation was the creation of a Steering Group to act as an advisory panel on strategy that guides through the development of culturally accessible service provision and facilitate ongoing relationships and engagement with BAME communities.

\section{P-46 'TELL US THERE IS NO CURE'- BAME COMMUNITIES SEEK CLEAR COMMUNICATION TO PREPARE FOR DYING}

Tricia Wilcocks, Joanne Leung. ellenor Gravesend, Kent, UK

\subsection{6/bmjspcare-2017-hospice.73}

Background Black, Asian and Minority Ethnic (BAME) groups have less access to palliative care due to deficient knowledge and awareness, culturally inappropriate services, communication barriers and more (Evans et al., 2011; Koffman, 2014; Calanzani et al., 2013; Smith et al., 2015). To support person-centred care (The Health Foundation, 2014) and to exchange skills and knowledge, a group of palliative care providers, charities and voluntary organisations, minority ethnic groups and academic researchers formed a Learning Alliance (LA). The LA attained funding from Health Education England to organise a consultation event with BAME groups and healthcare service providers, in order to examine and improve the existing palliative care services.

Aims Enhancing awareness of palliative care services. Improve understanding of how to engage with BAME groups at end of life.

Methods The consultation event introduced palliative care services to BAME groups, followed by group discussions exploring barriers of assessing the service, challenges in coping in the last year of life for a family member and understanding how best to communicate with local communities. The discussion summary was then relayed to healthcare service providers to improve service development for BAME communities.

Results 82 people attended, including representatives from religious and faith groups, carer support and commissioning groups. BAME communities gave some clear messages:

- 'Tell us there is no cure, so we can work on life we have left and prepare for death.'

- Use every means possible, radio, social media, events and posters, to continuously promote awareness.

- Use of confusing or misleading language to avoid the pain and reality of dying denies the opportunity to prepare for death.

Conclusion Service providers should utilise a wide range of media to explain available healthcare services but communication about end of life and palliative care needs to be simplified for minority groups. The LA was compelled to facilitate further outreach work with ethnic groups, to improve the quality of care and address unmet needs.

\section{P-47 A LEARNING ALLIANCE: EXPLORING PALLIATIVE CARE ISSUES AMONG ETHNIC GROUPS IN SOUTH EAST ENGLAND}

Joanne Leung. ellenor Gravesend, Kent, UK

10.1136/bmjspcare-2017-hospice.74

Background National Census (2011) (Office for National Statistics, 2012) indicated that the South East region had 9.3\% of non-white ethnic groups; yet, these groups had lower access, usage and satisfaction rates to palliative care services compared to people of White ethnicity (Calanzani et al., 2013; Dixon et al., 2015). In order to cater for the various needs of the local service users in a sustainable manner, a Learning Alliance (LA) was formed in South East England. This LA was comprised of palliative care providers, charities and voluntary organisations, minority ethnic groups and academic researchers, with funding for events provided by the local Health Education England network.

Aims By working collaboratively across the LA, it is anticipated that the emerging supportive and palliative care needs from the local population will be identified, mapped and addressed.

Methods The LA would organise two consultation events, which were designed for the Black, Asian, Eastern European, Romany and Traveller ethnic groups, to explore issues in providing and accessing palliative and end of life care services. The summary of these consultations was conveyed to healthcare service providers and expected to lead to potential research projects.

Results The LA has built a consolidated and viable network to support the healthcare service providers and users to enhance the uptake of the palliative care services, as well as to share expertise and practices with one another. Its consultation events and potential future research projects help the stakeholders to recognise the shortfalls of the existing services in order to rectify the inequalities within the healthcare services. Conclusion Reaching out and working alongside the health care service providers and minority ethnic groups allow both parties to increase awareness of the diversity needs and the suitability of the palliative care services. In the long term, the LA will be attempting to transfer and apply its findings to the wider minority population groups.

\section{P-48 THE DISADVANTAGED DYING: EXPLORING THE END OF LIFE PRIORITIES OF HOMELESS ADULTS IN THE UK}

Wendy Ann Webb, Theresa Mitchell, Brian Nyatanga, Paul Snelling. University of Worcester, UK

\subsection{6/bmjspcare-2017-hospice.75}

Background With limited resources and no stable accommodation, people who are homeless arguably have greater need of palliative care support than the rest of society when they face the end of life. However, they consistently fail to access palliative care services (Care Quality Commission, 2016) and while there is much in the literature surrounding the barriers to appropriate health care (Hudson et al., 2016), their specific 